\title{
Eficiência do recobrimento de sementes de soja em equipamento com sistema de aspersão
}

\author{
Coating efficiency of soybean seeds in equipment with spray system
}

\author{
Marcos Paulo Ludwig' Orlando Antônio Lucca Filho ${ }^{\mathrm{II}}$ Leopoldo Baudet ${ }^{\mathrm{II}}$ \\ Luiz Marcelo Costa Dutra' ${ }^{\mathrm{III}}$ Suemar Alexandre Gonçalves Avelar ${ }^{\text {IV }}$ Renato Lopes Crizel ${ }^{\mathrm{IV}}$ \\ Sandro de Oliveira ${ }^{\mathrm{IV}}$
}

RESUMO

O trabalho tem o objetivo de avaliar o tratamento e o recobrimento de sementes de soja em um equipamento com sistema de aspersão da marca Grazmec Spray System ${ }^{\circledR}$. O experimento foi realizado na Faculdade de Agronomia Eliseu Maciel (FAEM) da Universidade Federal de Pelotas, RS, Brasil. Os tratamentos foram: 1) testemunha (sem passagem pelo equipamento), 2) fungicida, 3) aminoácido, 4) polímero, 5) fungicida + aminoácido, 6) fungicida + inseticida, 7) fungicida + polímero, 8) fungicida + inseticida + polímero e 9) fungicida + aminoácido + inseticida, aplicados com o equipamento. Para avaliar o experimento, foram determinados o grau de umidade, emergência em campo, índice de velocidade de emergência, massa de 1000 sementes e intensidade de cobertura das sementes. De acordo com os resultados obtidos, verificouse que o aumento no grau de umidade das sementes de soja tratadas elou recobertas com o equipamento de sistema de aspersão é inferior a 1\%. A emergência de plântulas, índice de velocidade de emergência e a massa de 1000 sementes não foram afetados pelo tratamento elou recobrimento realizado com o sistema de aspersão. $O$ uso de polímero melhora o recobrimento das sementes no equipamento com sistema de aspersão. Porém, o equipamento deve ser regulado a cada mudança de produto elou semente para que o recobrimento seja eficaz.

Palavras-chave: armazenamento de sementes, beneficiamento, Glycine max, tratamento de sementes, umidade.

\begin{abstract}
The objective of this paper was to evaluate the treatment and coating of soybean seed using equipment with spray system Grazmec ${ }^{\circledR}$. The experiment was carried out in the Faculdade de Agronomia Eliseu Maciel of the Universidade Federal de Pelotas, Rio Grande do Sul state, Brazil. The treatments were: 1) control (without equipment), 2) fungicide, 3) amino acid, 4) polymer, 5) fungicide + amino acid, 6) fungicide + insecticide, 7) fungicide + polymer, 8) fungicide + insecticide + polymer, 9) fungicide + amino acid + insecticide, all applied with the equipment. To evaluate the experiment the moisture content determination, field emergence, index of emergency speed, weight of 1000 seeds and intensity of coverage was carried out. The results showed that soybean seed treated and/or coated didn't reach more than $1 \%$ with the treatment. The field emergence, index of emergency speed and weight of 1000 seeds weren't affected by treatment and/or coating by spray system. The use of the polymer improves the seed coating when the spray system was used. However the equipment should be regulated when there is change of the product and/ or seed to obtain an appropriate coating.
\end{abstract}

Key words: storage, conditioning, Glycine max, seed treatment, moisture.

\section{INTRODUÇÃO}

O recobrimento das sementes consiste no revestimento destas com uma camada sólida muito fina

'Instituto Federal de Educação, Ciência e Tecnologia do Rio Grande do Sul (IFRS), Campus Ibirubá, 98200-000, Ibirubá, RS, Brasil. E-mail: plmarcos1@yahoo.com.br. Autor para correspondência.

"Departamento de Fitotecnia, Universidade Federal de Pelotas (UFPel), Pelotas, RS, Brasil.

IIIDepartamento de Fitotecnia, Centro de Ciências Rurais (CCR), Universidade Federal de Santa Maria (UFSM), Santa Maria, RS, Brasil.

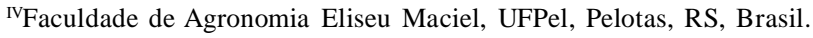


(film coating) formada de sólidos dissolvidos ou suspensos em água. Esta camada forma uma capa, que reveste de forma completa e uniforme toda a cobertura protetora natural das sementes. Assim tratadas, as sementes mantêm-se individualizadas, podendo haver ou não modificação de sua massa e da sua forma original (MEDEIROS et al., 2004). Mas não basta um tratamento de sementes de altíssimo nível se a semente não atende aos atributos genéticos, físicos, fisiológicos e sanitários. A produção de uma cultura é dependente muito mais das características intrínsecas da semente do que do tratamento nela aplicado. Desta maneira, o recobrimento auxilia no desempenho da semente no campo.

Há uma carência de equipamentos nacionais para recobrimento de sementes, sendo necessária a importação de maquinário específico para recobri-las. Esses equipamentos têm como finalidade peliculizar sementes, ou seja, são capazes de construir uma camada de filme constituída de polímeros e outras substâncias de recobrimento. $\mathrm{O}$ desenvolvimento de máquinas para recobrimento por empresas nacionais reduziria o custo do tratamento, pois os equipamentos importados têm custo elevado devido à cotação da moeda e do transporte da máquina do país de origem até o Brasil. É preciso ressaltar os problemas com assistência técnica e aquisição de peças que devem vir do país de fabricação do equipamento.

Há aspectos que merecem destaque quando se trata de equipamentos para tratamento de sementes, como a maior disponibilidade de equipamentos para aplicação em forma líquida, o uso de menores dosagens, novos produtos, necessidade de maior precisão e monitoramento, melhores periféricos e certificação do tratamento para sementes de alto valor. O uso do recobrimento de sementes vem aumentando e, portanto, o desenvolvimento e a avaliação de equipamentos para esta tecnologia são necessários.

$\mathrm{O}$ equipamento com sistema de aspersão Spray System ${ }^{\circledR}$ foi desenvolvido dentro dos padrões exigidos pelas normas técnicas, visando representar um novo conceito no tratamento de sementes, diferentemente das tratadoras convencionais que utilizam o sistema de "copinhos" para dosar o produto químico. O sistema é formado por discos impulsores que realizam o tratamento de maneira mais uniforme, pois possibilitam a formação de uma névoa de produto que será depositada sobre a semente. Além da possibilidade de regulagem da dosagem do produto líquido, também regula a vazão de sementes pelo sistema de "chapéu chinês". A regulagem da vazão de produto é feita através de sistema eletrônico que proporciona uma aplicação exata, evitando desperdícios ou subdosagens. Além da caixa para produto líquido e em pó, o equipamento possui dois recipientes abastecedores com regulagem independente, pois cada um possui sua caixa de comando (GRAZMEC, 2007).

Nesse sentido, o presente trabalho teve o objetivo de avaliar o recobrimento de sementes de soja em uma máquina de tratamento de sementes com sistema de aspersão Spray System ${ }^{\circledR}$, em função da variação do grau de umidade das sementes, qualidade fisiológica das sementes tratadas e/ou recobertas e pela intensidade do recobrimento.

\section{MATERIAL E MÉTODOS}

O experimento foi realizado na Unidade de Beneficiamento de Sementes (UBS), as avaliações laboratoriais foram realizadas no Laboratório Didático de Analise de Sementes e a parte de campo foi realizada na Área Experimental e Didática do Departamento de Fitotecnia, todos pertencentes à Faculdade de Agronomia Eliseu Maciel (FAEM) da UFPel.

$\mathrm{O}$ equipamento utilizado foi da marca Grazmec modelo "MTS Spray System ${ }^{\circledR} 120 ”$ o qual apresenta o sistema de discos impulsores, com regulagem da dose através do painel de comandos. A regulagem da passagem das sementes pelo equipamento é alterada pela altura do "chapéu chinês". Para adequar as doses do polímero com os produtos utilizados e a regulagem da máquina para o recobrimento foram realizados dois testes preliminares na UBS. Os motores do equipamento apresentam a voltagem de $220 \mathrm{~V}$ e potência de meio e um cv, a moega da semente é feita de PVC totalizando um peso de $160 \mathrm{~kg}$. A altura e a largura do equipamento são de 1,5 e 1,21m, respectivamente, e o comprimento total é de $2 \mathrm{~m}$.

Foi alterada a altura do "chapéu chinês" e modificada a dose de produto através do comando de vazão. Para verificar a eficiência do recobrimento, foram tratados $30 \mathrm{~kg}$ de sementes, buscando o melhor recobrimento pela escala de BURRIS (s.d). A regulagem que proporcionou melhor recobrimento foi com capacidade de tratamento de $50 \mathrm{~kg}$ de sementes em 92 segundos.

Visando a não aumentar de forma demasiada o conteúdo de umidade das sementes de soja, estas foram tratadas com volume de calda total de $600 \mathrm{~mL}$ para $100 \mathrm{~kg}$ de sementes, conforme indicação da REUNIÃODE PESQUISADE SOJA DA REGIÃO SUL (2006). Os produtos utilizados foram o fungicida Maxin $\mathrm{XL}^{\circledR}$ com o princípio ativo Fludioxonil + Metalaxil $M$; o inseticida Cruiser $^{\circledR}$ a base de Thiametoxam; o aminoácido PT-4- $0^{\circledR}$ e os produtos para o recobrimento polímero Polyseed $\mathrm{CF}^{\circledR}+$ Colorseed $^{\circledR}$. Os tratamentos 
aplicados com o equipamento foram: 1) testemunha, 2) fungicida $(100 \mathrm{~mL}$ para $100 \mathrm{~kg}$ de sementes), 3) aminoácido (150mL para $100 \mathrm{~kg}$ de sementes), 4) polímero (100mL para $100 \mathrm{~kg}$ de sementes), 5) fungicida + aminoácido, 6) fungicida + inseticida $(100 \mathrm{~mL}$ para $100 \mathrm{~kg}$ de sementes), 7) fungicida + polímero, 8) fungicida + inseticida + polímero e 9) fungicida + aminoácido + inseticida. O restante da calda foi completada com água até atingir o volume de $600 \mathrm{~mL}$ para $100 \mathrm{~kg}$ de sementes.

A cultivar de soja utilizada foi 'CD 219 RR', classificada na peneira de furo redondo de $5,0 \mathrm{~mm}$, a qual foi armazenada por cinco meses após a colheita em condição não controlada no município de Capão do Leão, RS, até a realização dos tratamentos que ocorreram no mês de outubro de 2007.

Realizou-se avaliação do grau de umidade, massa de 1000 sementes, intensidade de cobertura, emergência em campo e índice de velocidade de emergência. $\mathrm{O}$ grau de umidade foi determinado pelo método da estufa a $105 \pm 3^{\circ} \mathrm{C}$ por 24 horas, sendo utilizadas duas repetições para cada unidade experimental (BRASIL, 2009). Esta avaliação foi realizada aos zero, 60, 120 e 180 dias após o tratamento das sementes. Para a determinação da massa de 1000 sementes, foram tomadas oito repetições contendo cada uma 100 sementes e pesadas em balança analítica; posteriormente, todas as amostras foram transformadas para teor de água de 13\%, determinando-se a massa de 1000 sementes, de acordo com o indicado nas RAS (BRASIL, 2009).

A intensidade de cobertura das sementes foi determinada visualmente, classificando as sementes quanto à intensidade da pigmentação (devido à cobertura do polímero e corante) em uma escala de zero a dez, em que zero corresponde às sementes sem cobertura e dez às sementes com cobertura excelente, segundo escala de BURRIS (s.d). Para essa determinação, foram utilizadas 10 sementes de cada unidade experimental.

As avaliações de emergência em campo e índice de velocidade de emergência foram realizadas aos zero, 60 e 120 dias após o tratamento das sementes. Para a determinação da emergência em campo, foram utilizadas quatro repetições de 50 sementes de cada unidade experimental. As avaliações foram realizadas aos 14 dias após a semeadura, de acordo com TILLMANN \& MIRANDA (2006). O índice de velocidade de emergência foi calculado conjuntamente com a emergência em campo. As contagens para determinação do índice de velocidade de emergência foram realizadas diariamente do quinto dia após a semeadura até a estabilização da emergência, posteriormente calculou-se o Índice de Velocidade de
Emergência, de acordo com TILLMANN \& MIRANDA (2006). Foram contabilizadas como plântulas emergidas as que apresentaram dois centímetros $(2,0 \mathrm{~cm})$ de comprimento acima da superfície do solo.

As análises estatísticas foram realizadas pela análise de variância (ANOVA) e teste de Dunnett a 5\% de significância para a comparação de médias. Para avaliar a intensidade de cobertura das sementes, foram realizadas duas análises estatísticas dos dados obtidos da escala de 0 a 10 proposta por BURRIS (s.d.). A primeira foi o teste de Scott-Knott a 5\% de significância e a segunda foi com a estatística descritiva utilizando gráfico de caixa.

\section{RESULTADOS E DISCUSSÃO}

Os resultados do grau de umidade das sementes de soja logo após o tratamento na máquina demonstraram haver aumento da umidade na maioria dos tratamentos, quando comparados com a testemunha (Tabela 1). Somente os tratamentos: fungicida, aminoácido e fungicida + aminoácido não diferiram da testemunha quanto à absorção de água pelas sementes após o tratamento. $\mathrm{O}$ tratamento que teve maior incremento no grau de umidade durante a aplicação dos produtos foi o fungicida + inseticida + polímero, no qual houve um incremento de 0,9 pontos percentuais. $\mathrm{O}$ incremento no grau de umidade está relacionado com a absorção de água pelas sementes quando estas passavam pelo equipamento.

Na segunda avaliação aos 60 dias, somente os tratamentos fungicida e aminoácido diferiram da testemunha, a diferença do grau de umidade foi de 0,8 pontos percentuais. Nas avaliações aos 120 e 180 dias após o tratamento, não foi observada diferença entre os tratamentos e a testemunha para o grau de umidade.

Durante o armazenamento, houve alteração na umidade em todos os tratamentos. A redução do grau de umidade na avaliação aos 60 dias após o tratamento foi de 2,7 pontos percentuais, já na avaliação aos 120 dias após tratamento, ocorreu um aumento de 0,9 pontos percentuais em comparação com a avaliação aos 60 dias. Na última avaliação, houve novamente redução do grau de umidade em 0,7 pontos percentuais, o que demonstra a tendência das sementes em se equilibrar com o meio ambiente onde foram armazenadas. Após a primeira redução do grau de umidade, este não ultrapassou $13 \%$, valor utilizado para armazenamento. A variação do grau de umidade está relacionada com a higroscopidade das sementes de soja, ou seja, têm a capacidade de trocar umidade com o ambiente, até entrar em equilíbrio com o meio (BAUDET \& VILLELA, 2006). 
Tabela 1 - Grau de umidade (\%), massa de 1000 sementes (g) e eficácia do recobrimento de sementes de soja, pela escala de 0 a 10 de BURRIS (s.d.), sem tratamento (testemunha) e tratadas e/ou recobertas com polímeros, em equipamento com sistema de aspersão, em quatro avaliações ( $0,60,120$ e 180 dias após tratamento).

\begin{tabular}{|c|c|c|c|c|}
\hline \multirow[t]{2}{*}{ Tratamentos } & \multicolumn{4}{|c|}{ Épocas de avaliação (dias) } \\
\hline & 0 & 60 & 120 & 180 \\
\hline Testemunha & 13,7 & 10,9 & 12,5 & 11,6 \\
\hline Fungicida & 13,8 & $11,7^{*}$ & 12,2 & 11,5 \\
\hline Aminoácido & 13,9 & $11,7 *$ & 12,2 & 11,6 \\
\hline Polímero & $14,1^{*}$ & 11,4 & 12,3 & 11,6 \\
\hline Fungicida + aminoácido & 13,9 & 11,5 & 12,3 & 11,5 \\
\hline Fungicida + inseticida & $14,2^{*}$ & 11,4 & 12,3 & 11,7 \\
\hline Fungicida + polímero & $14,2^{*}$ & 11,6 & 12,2 & 11,7 \\
\hline Fungicida + inseticida + polímero & $14,6^{*}$ & 11,2 & 12,5 & 11,6 \\
\hline Fungicida + aminoácido + inseticida & $14,4^{*}$ & 11,5 & 12,5 & 11,6 \\
\hline Média & 14,1 & 11,4 & 12,3 & 11,6 \\
\hline $\mathrm{CV}$ & 0,85 & 2,24 & 1,66 & 1,71 \\
\hline Tratamentos & \multicolumn{4}{|c|}{-----Massa de 1000 sementes (g)*------ } \\
\hline Testemunha & \multicolumn{3}{|c|}{125,39} & $0 \mathrm{e}$ \\
\hline Fungicida & \multicolumn{2}{|c|}{125,86} & \multicolumn{2}{|c|}{$2,5 \mathrm{~d}$} \\
\hline Aminoácido & \multicolumn{2}{|c|}{123,45} & \multicolumn{2}{|c|}{$2,7 \mathrm{~d}$} \\
\hline Polímero & \multicolumn{2}{|c|}{125,69} & \multicolumn{2}{|c|}{$6,2 \mathrm{~b}$} \\
\hline Fungicida + aminoácido & \multicolumn{2}{|c|}{125,61} & \multicolumn{2}{|c|}{$4,1 \mathrm{c}$} \\
\hline Fungicida + inseticida & \multicolumn{2}{|c|}{125,73} & \multicolumn{2}{|c|}{$3,1 \mathrm{~d}$} \\
\hline Fungicida + polímero & \multicolumn{2}{|c|}{125,75} & \multicolumn{2}{|c|}{$5,8 \mathrm{~b}$} \\
\hline Fungicida + inseticida + polímero & \multicolumn{2}{|c|}{125,49} & \multicolumn{2}{|c|}{$8 \mathrm{a}$} \\
\hline Fungicida + aminoácido + inseticida & \multicolumn{2}{|c|}{124,59} & \multicolumn{2}{|c|}{$4,5 \mathrm{c}$} \\
\hline Média & \multicolumn{2}{|c|}{125,3} & \multicolumn{2}{|c|}{4,1} \\
\hline $\mathrm{CV}$ & \multicolumn{2}{|c|}{1,01} & \multicolumn{2}{|c|}{13,28} \\
\hline
\end{tabular}

(*) Diferença significativa em relação à testemunha pelo teste bilateral de Dunnet a 5\% de significância.

${ }^{(+)}$Tratamentos seguidos pela mesma letra pertencem ao mesmo grupo pelo teste de Scott Knott a 5\% de significância.

Vale ressaltar a importância da regulagem do equipamento, que deve ser realizada de forma precisa, evitando desperdício de produtos pela aplicação de um volume de calda acima do indicado, o que poderia resultar em aumento demasiado no grau de umidade das sementes. Para obtenção de um recobrimento de qualidade, é necessário alterar a quantidade de semente que passa pelo equipamento e consequentemente de produto a ser aplicado em determinado tempo. Dessa forma, evitam-se os excessos ou déficit de calda, o que pode ocasionar aumento no grau de umidade.

Com relação à massa de 1000 sementes (Tabela 1), não foi observada diferença entre os tratamentos e a testemunha, o que demonstra não haver variação da massa das sementes devido o tratamento e/ou recobrimento no equipamento utilizado. Resultado que está relacionado com a pouca deposição de produtos na superfície da semente, para formar ofilm coating.
O tratamento que propiciou o melhor recobrimento (Tabela 1) foi o de fungicida + inseticida + polímero, pois obteve nota 8 segundo a escala de BURRIS (s.d.). Em seguida, o melhor recobrimento foi formado pelos tratamentos somente com polímero e o com fungicida + polímero, mostrando que a utilização do polímero melhora a aparência das sementes com o recobrimento. Cabe ressaltar a não-formação de um grupo para todos os tratamentos de recobrimento com polímero, o que pode estar relacionado com a regulagem do equipamento em teste. Quando foi realizada a regulagem do equipamento, foi utilizada a calda com o polímero. Porém o tratamento com fungicida + inseticida + polímero demonstrou ser mais eficiente no recobrimento das sementes. Com esses resultados, ressalta-se a importância dos testes preliminares, tanto no laboratório como no equipamento utilizado para o recobrimento das sementes. Isso faz recomendar uma regulagem do equipamento para cada tratamento que será aplicado, no caso, o que resulte em melhor recobrimento das sementes. 
Os demais tratamentos testados ficaram agrupados no terceiro (fungicida + aminoácido e fungicida + aminoácido + inseticida) e no quarto grupos (fungicida aminoácido e fungicida + inseticida). Esses tratamentos têm em comum a ausência de recobrimento devido às características dos produtos utilizados, que não foram polímeros. No caso, pode-se notar uma boa combinação entre fungicida e aminoácido, os quais individualmente pertenceram ao grupo dos piores recobrimentos e em combinação passaram para outro grupo de melhor cobertura. Como não foi aplicado nenhum tratamento na testemunha, esta obteve nota zero.

A análise estatística descritiva dos dados de recobrimento foi feita através da utilização de gráfico de caixa (Figura 1). O maior valor de mediana e de limite da haste superior (nota nove) foi observado no tratamento fungicida + inseticida + polímero, enquanto o limite da haste inferior ficou próximo de sete. Em relação à distribuição dos dados somente neste tratamento, foi observada uma simetria, em que a linha da mediana se encontra no centro dos quartis e as linhas do limite da haste superior e inferior têm aproximadamente o mesmo comprimento. A obtenção desses resultados demonstra a capacidade do equipamento em realizar recobrimento das sementes desde que regulado de forma correta, tanto na vazão de sementes como na dosagem e vazão dos produtos.

O tratamento somente com o polímero obteve o segundo maior valor do limite da haste superior e mediana, seguido pelo tratamento fungicida + polímero. Os valores do limite da haste inferior foram semelhantes para os dois tratamentos. A distribuição dos dados para os dois tratamentos foi assimétrica, porém, para o tratamento polímero, e assimétrica à direita, pois o valor da mediana está mais próximo ao primeiro quartil. Já o tratamento fungicida + polímero possui distribuição assimétrica à esquerda, ou seja, a linha da mediana se encontra mais próxima do terceiro quartil.

Os tratamentos sem polímero que obtiveram os valores de mediana em torno de quatro e cinco foram aqueles com fungicida + aminoácidos + inseticida e fungicida + aminoácido. Os demais obtiveram valores de mediana inferiores a quatro. $O$ tratamento com limite da haste superior maior é o fungicida + aminoácido + inseticida, os quais se aproximavam de cinco. Os menores valores do limite da haste inferior estão ao

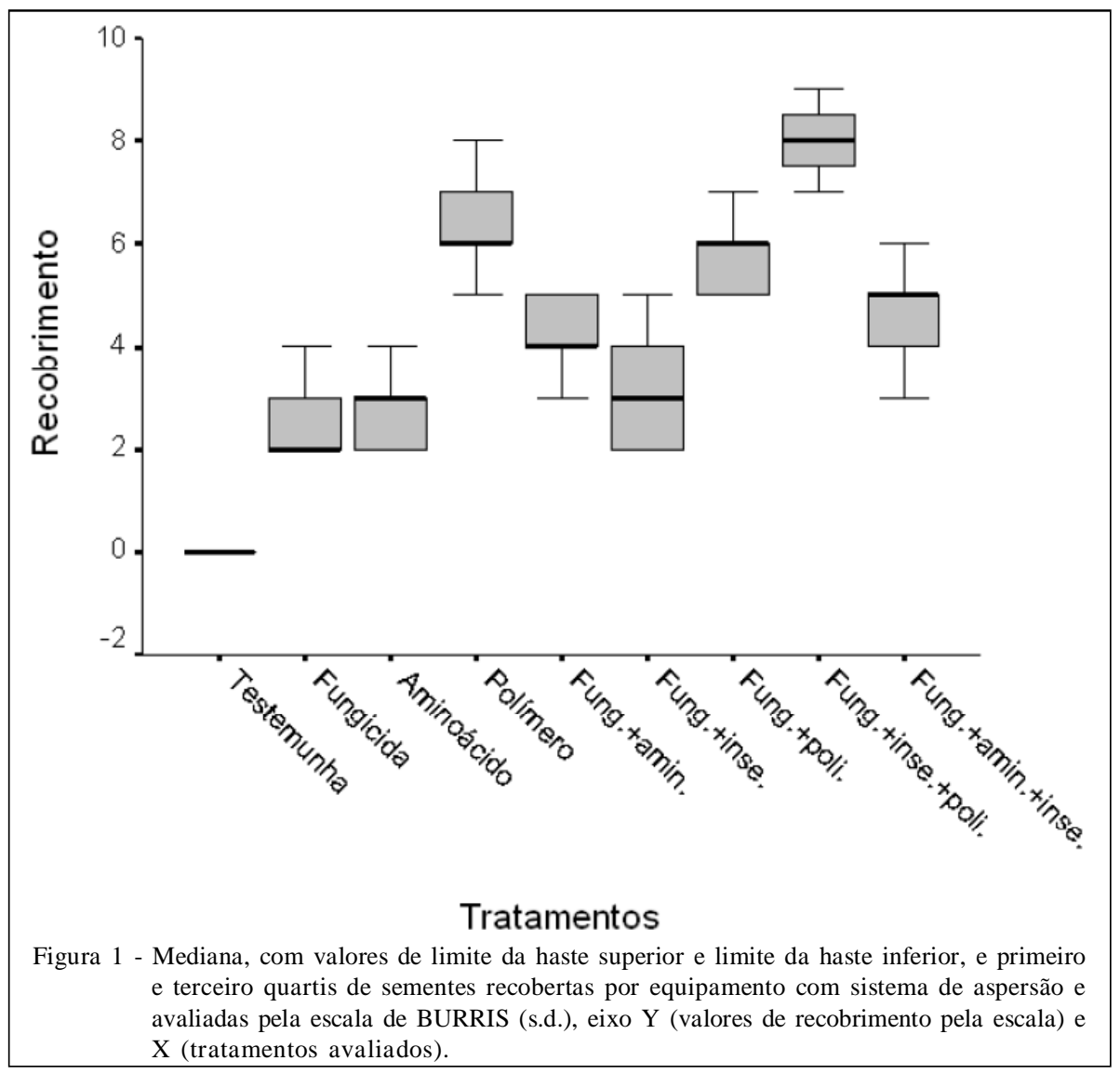

Ciência Rural, v.41, n.4, abr, 2011. 
redor de dois e foram observados nos tratamentos com fungicida, aminoácido e fungicida + inseticida.

$\mathrm{O}$ recobrimento das sementes com o equipamento por aspersão, utilizando polímeros, é eficaz em relação os tratamentos sem a utilização de polímero. Porém, é necessário realizar testes preliminares para adequar a dose do polímero para a perfeita regulagem do equipamento, buscando obter a máxima cobertura das sementes. Destaca-se também que a regulagem do equipamento pode mudar conforme o produto empregado e as características físicas das sementes utilizadas. Trabalhando com recobrimento de sementes de soja BAYS et al. (2007); PEREIRA et al. (2007) constataram resultado semelhante: a aplicação de polímero assegurou melhor uniformidade aos tratamentos (aderência, distribuição e coloração) e também não prejudicou a qualidade e desempenho das sementes testadas.

Para detectar os efeitos do tratamento na máquina sobre a qualidade fisiológica das sementes, foram realizados os testes de emergência a campo e índice de velocidade de emergência (Tabela 2). Os resultados demonstram não haver efeito negativo do tratamento de sementes com o equipamento, tanto para emergência em campo, como para o índice de velocidade de emergência, quando comparado com a testemunha. Tanto para a avaliação logo após o tratamento como nas avaliações seguintes, não houve diferença, o que indica que não houve efeito significativo nem imediato nem latente do tratamento e/ou recobrimento das sementes de soja. Resultados semelhantes foram obtidos por DINIZ et al. (2006), que trabalharam com sementes de alface, e o revestimento com aminoácido não afetou a emergência e o índice de velocidade de emergência. Avaliando o efeito do polímero em semente de soja, PEREIRA et al. (2009) também constataram que não houve efeito da aplicação do polímero na emergência e índice de velocidade de emergência (IVE).

Porém, pode-se observar que a emergência em campo das sementes foi visivelmente afetada após

Tabela 2 - Emergência em campo (\%) e índice de velocidade de emergência de sementes de soja sem tratamento (testemunha) e tratadas e/ou recobertas com polímeros, em equipamento com sistema de aspersão, em três épocas (Semeaduras em outubro, dezembro de 2007 e fevereiro de 2008; 0, 60 e 120 dias após o tratamento, respectivamente).

\begin{tabular}{|c|c|c|c|}
\hline \multirow{2}{*}{ Tratamentos } & \multicolumn{3}{|c|}{-Épocas de avaliação (dias) ------ } \\
\hline & 0 & 60 & 120 \\
\hline \multicolumn{4}{|c|}{ - } \\
\hline Testemunha & 72 & 69 & 39 \\
\hline Fungicida & 78 & 72 & 54 \\
\hline Aminoácido & 68 & 68 & 45 \\
\hline Polímero & 73 & 65 & 41 \\
\hline Fungicida + aminoácido & 72 & 67 & 41 \\
\hline Fungicida + inseticida & 70 & 71 & 40 \\
\hline Fungicida + polímero & 73 & 70 & 41 \\
\hline Fungicida + inseticida + polímero & 69 & 72 & 44 \\
\hline Fungicida + aminoácido + inseticida & 73 & 68 & 42 \\
\hline Média & 72 & 69 & 43 \\
\hline $\mathrm{CV}$ & 12,68 & 6,06 & 12,00 \\
\hline Testemunha & 9,22 & 14,02 & 7,75 \\
\hline Fungicida & 8,57 & 12,74 & 6,41 \\
\hline Aminoácido & 9,44 & 14,38 & 9,41 \\
\hline Polímero & 8,65 & 13,12 & 7,44 \\
\hline Fungicida + aminoácido & 7,36 & 12,89 & 6,90 \\
\hline Fungicida + inseticida & 7,69 & 12,32 & 6,82 \\
\hline Fungicida + polímero & 8,86 & 14,21 & 6,84 \\
\hline Fungicida + inseticida + polímero & 9,05 & 13,16 & 6,97 \\
\hline Fungicida + aminoácido + inseticida & 9,10 & 13,91 & 7,77 \\
\hline Média & 8,66 & 13,42 & 7,37 \\
\hline $\mathrm{CV}$ & 12,64 & 6,44 & 19,08 \\
\hline
\end{tabular}

(*) diferença significativa em relação à testemunha pelo teste bilateral de Dunnet a 5\% de significância. 
60 dias de armazenamento, provavelmente em função das condições ambientais durante o armazenamento, já que houve aumento do grau de umidade das sementes após esse período (Tabela 1). O mesmo efeito foi observado no IVE após 60 dias de armazenamento.

Dessa maneira, pode-se verificar que o aumento do grau de umidade não é fator limitante para a utilização do equipamento em teste para recobrimento de sementes. O tratamento aumentou o grau de umidade; no entanto, o aumento não chegou a $1 \%$ e este também ocorre nos tratamentos sem polímero, em que o equipamento é comumente utilizado.

Também não foi detectado efeito dos tratamentos nos testes em campo, pois, do mesmo modo que não ocorreu redução pelo tratamento das sementes com o equipamento, também não ocorreu incremento significativo pelos tratamentos realizados. Resultados semelhantes foram observados por PEREIRA et al. (2007), que verificaram desempenho semelhante das sementes de soja submetidas ou não a peliculização até o sexto mês de armazenamento. O tratamento somente com fungicida apresentou os valores mais altos de emergência em campo nas três épocas de avaliação, e o tratamento com aminoácido apresentou o maior valor de índice de velocidade de emergência, mas não diferiram.

\section{CONCLUSÃO}

O aumento no grau de umidade das sementes de soja tratadas e/ou recobertas com o equipamento de sistema de aspersão é inferior a $1 \%$. A emergência de plântulas, índice de velocidade de emergência e a massa de 1.000 sementes não foram afetadas pelo tratamento e/ou recobrimento testados. O uso de polímero melhora a eficiência do recobrimento das sementes tratadas. Para que o recobrimento seja eficaz o equipamento deve ser regulado a cada mudança de produto e/ou semente.

\section{REFERÊNCIAS}

BAUDET, L.; VILLELA, F.A. Armazenamento de sementes. In.: PESKE, S.T.et al. (Eds.). Sementes: fundamentos científicos e tecnológicos. 2ed. Pelotas: UFPel, 2006. Cap.7, p.427-470.

BAYS, R. et al. Recobrimento de sementes de soja com micronutrientes, fungicida e Polímero. Revista Brasileira de Sementes, v.29, n.2, p.60-67, 2007.

BRASIL. Ministério da Agricultura, Pecuária e Abastecimento. Regras para análise de sementes. Brasília: Mapa/ACS, 2009. 399p.

BURRIS, J. Film coating recovery quality rating scale. Ames, IA: Seed Science Center, Iowa State University, s.d. 1p.

DINIZ, K.A. et al. Incorporação de microrganismos, aminoácidos, micronutrientes e reguladores de crescimento em sementes de alface pela técnica de peliculização. Revista Brasileira de Sementes, v.28, n.3, p.37-43, 2006.

GRAZMEC. Manual de operação e catálogo de peças spray system. 33p. Disponível em: 〈www.grazmec.com.br〉. On line. Acesso em: 05 nov.2007.

MEDEIROS, E.M. et al. Modificações na condição física das sementes de cenoura em equipamento de recobrimento. Revista Brasileira de Sementes, v.26, n.2, p.70-75, 2004.

PEREIRA, C.E. et al. Desempenho de sementes de soja tratadas com fungicidas e peliculizadas durante o armazenamento. Ciência e Agrotecnologia, v.31, n.3, p.656-665, 2007. Disponível em: <http://www.scielo.br/scielo.php?pid=S1413$70542007000300009 \&$ script $=$ sci_arttext\&tlng=en>. Acesso em: 06 mar. 2010. doi: 10.1590/S1413-70542007000300009.

PEREIRA, C.E. et al. Tratamento fungicida de sementes de soja inoculadas com Colletotrichum truncatum. Ciência Rural, v.39, n.9, p.2390-2395, 2009. Disponível em: <http:// submission.scielo.br/index.php/cr/article/view/7394/1628>. Acesso em: 06 mar. 2010. doi: 10.1590/S010384782009005000215 .

REUNIÃO DE PESQUISA DE SOJA DA REGIÃO SUL. Indicações técnicas para a cultura da soja no Rio Grande do Sul e em Santa Catarina 2006/2007. Pelotas, 2006. $237 \mathrm{p}$.

TILLMANN, M.Â.A.; MIRANDA D.M. de. Análise de xementes. In.: PESKE, S.T. et al. (Eds.). Sementes: fundamentos científicos e tecnológicos. 2.ed. Pelotas: UFPel, 2006. Cap.3, p.159-257. 